\title{
Is there a diffusion of alkali in the activation of dissolving cellulose pulp at low NAOH stoichiometric excess?
}

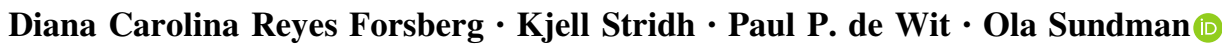

Received: 7 May 2018/ Accepted: 2 November 2018/Published online: 10 November 2018

(C) The Author(s) 2018

\begin{abstract}
We conducted a quantitative study, following the degree of activation (i.e. the transformation to alkali cellulose, denoted as DoA) over time for dissolving cellulose pulp treated with different $[\mathrm{NaOH}]$ at low $\mathrm{NaOH} /$ anhydroglucose unit stoichiometric ratio (denoted as $(\mathrm{r}) \leq 2.6$ ). Our quantitative approach was based on Raman spectroscopy data, evaluated by partial least squares regression modelling. The results show strong influence of the (r) on DoA (increasing from DoA $=45 \%$ at $(r)=0.8$, to DoA $=85 \%$ at $(r)=2.6)$, and its complex dependence on $[\mathrm{NaOH}]$. At $(\mathrm{r})=0.8$ the highest DoA (DoA $\gtrsim 60 \%$ ) was found at $30 \%[\mathrm{NaOH}]$, while at $(\mathrm{r})=1.3$ it was found at $20 \%[\mathrm{NaOH}] \quad(\mathrm{DoA} \gtrsim 80 \%$ ). Although activation of cellulose happens in minutes
\end{abstract}

at the studied temperature $\left(30{ }^{\circ} \mathrm{C}\right)$, it was found that the reaction may be slow when a low (r) is used. A gradual increase of the DoA from $\approx 30$ to $\approx 70 \%$ in time was seen when samples were activated with $30 \%$ $[\mathrm{NaOH}]$ at $(\mathrm{r})=0.8$. At the same $(\mathrm{r})$, a similar increase of DoA from $\approx 30$ to $\approx 60 \%$ was also observed when $40 \%[\mathrm{NaOH}]$ was used. Slow diffusion of $\mathrm{NaOH}$ through poorly swollen cellulose fibres is proposed as an explanation for this phenomenon. Lastly, solidstate CP/MAS NMR measurements suggest that at a fixed temperature, the Na-Cell allomorph mostly depends on $[\mathrm{NaOH}]$. However, in the transition area between Na-Cell I and Na-Cell II, its influence might be affected by (r).

Electronic supplementary material The online version of this article (https://doi.org/10.1007/s10570-018-2104-9) contains supplementary material, which is available to authorized users.

D. C. Reyes Forsberg · O. Sundman ( $\square)$

Department of Chemistry, Umeå University,

90187 Umeå, Sweden

e-mail: ola.sundman@umu.se

K. Stridh

AkzoNobel, 44485 Stenungsund, Sweden

P. P. de Wit

AkzoNobel, PO Box 5544, 6802 EM Arnhem,

The Netherlands 


\section{Graphical abstract}



Keywords Alkali cellulose - Activation · Polymorphs · Cellulose ether · Diffusion

\section{Introduction}

In the first step of manufacturing cellulose-based value-added products, e.g. viscose fibres and cellulose ethers, the cellulose, i.e. parallel crystalline structure cellulose I (Cell I), is treated with aqueous $\mathrm{NaOH}$ to alter its physical and chemical properties in a process called mercerisation. During mercerisation, Cell I transforms into a swollen crystalline structure, alkali cellulose (Na-Cell). This increases the reactivity of the cellulose and makes it more accessible for reagents to penetrate and react with the hydroxyl groups. Due to the importance of this process step, the cellulose$\mathrm{NaOH}$ reaction has been extensively studied, where research has tended to focus at a relatively high stoichiometric ratio of $\mathrm{NaOH} / \mathrm{AGU}$ (anhydroglucose unit), typically (r) $\geq 20$ (e.g. Albán Reyes et al. 2016; Philipp et al. 1983; Porro et al. 2007; Ranby 1952; Schenzel et al. 2009; Sobue and Kiessig 1939; Yue et al. 2013) rather than at low (r). Mercerising cellulose in excess of $\mathrm{NaOH}$ may be appropriate when making viscose fibres (Mozdyniewicz and Sixta 2012; Wilkes 2001), but less so in processes related to cellulose ethers. The use of such high (r) then leads to the formation of unwanted by-products, which are generated by the reactions of the added chemicals with water and excess $\mathrm{OH}^{-}$ions (e.g. Saxell et al. 2015). To avoid this, modern cellulose ethers production is done at low-water-content (LWC) mercerisation i.e. low $(\mathrm{r})((\mathrm{r})=1.1-5.0)$ in combination with high $[\mathrm{NaOH}]$ $([\mathrm{NaOH}]=40-50 \% \quad \mathrm{w} / \mathrm{w})$ (Berglund et al. 2009; Boström and Karlson 2013). Hereafter, we refer to low $(r)$ when mercerisation is done at $(r) \leq 5$.

The Na-Cell allomorph formed during the interaction of cellulose with an aqueous solution of $\mathrm{NaOH}$ as a function of temperature and $[\mathrm{NaOH}]$ using high (r) was earlier presented by Sobue and Kiessig (1939) where five different allomorphs $\mathrm{Na}-\mathrm{Cell}$ were reported when X-ray diffraction was used. Later, Porro et al. (2007) suggested a reconsideration of such Na-Cell allomorphs by using ${ }^{13} \mathrm{C} \mathrm{CP} / \mathrm{MAS}$ NMR. Only two types of Na-Cell were found, Na-Cell I and Na-Cell II, where Na-Cell I was more predominant at $[\mathrm{NaOH}]$ $\leq 25 \%$, while Na-Cell II dominated at $[\mathrm{NaOH}]$ $\geq 30 \%$. The transformation of these two allomorphs into an antiparallel chain structure, cellulose II (Cell II) is obtained by neutralising and drying (Langan et al. 2001; Okano and Sarko 1985). This transformation has been used as a standard procedure to investigate mercerisation (Gupta et al. 2013; Jin et al. 2016; Sisson and Saner 1941), and we used the same approach to define the degree of activation (DoA).

In mercerisation at higher (r), e.g. steeping, more contact between Cell I and NaOHaq take place, making mercerisation a rather quick process, however, highly affected by temperature and $[\mathrm{NaOH}]$ (Albán 
Reyes et al. 2016; Borysiak and Garbarczyk 2003; Ranby 1952; Sisson and Saner 1941). Despite these early observations, it remains unclear if this is the case for LWC mercerisation, where less contact between cellulose and $\mathrm{NaOHaq}$ takes place, and the system is drier compared to mercerisation at higher (r). In fact, in this type of mercerisation, it is essential to use a mixing system of high intensity, that helps to bring all the components together. Hence, it is of interest to know whether there is time dependence or diffusion of $\mathrm{NaOH}$ in this type of mercerisation or not. The study of the DoA over time is important for the cellulose ether producers, where a highly activate cellulose is desired, but the contact area between the cellulose and $\mathrm{NaOH}$ in their process conditions is relatively small. In a previous study, we have shown that during mercerisation at $\mathrm{LWC}$, the variation in (r) and $[\mathrm{NaOH}]$ becomes important for the DoA, while the temperature shows to be of less importance in such a heterogeneous system (Reyes et al. 2017). We also suggested that an additional diffusion-controlled mercerisation mechanism directs the mercerisation when $(r)=0.8$. This was based on the fact that DoA in ground cellulose pulp seemed to increase with time at the mentioned (r). This study, however, only covered a limited range of $[\mathrm{NaOH}]([\mathrm{NaOH}]=45-55 \%)$ and reaction time $(5$ and $25 \mathrm{~min}$ ). Therefore, the suggested mechanism is inconclusive. Hence, a comprehensive evaluation of the suggested diffusion-controlled mercerisation at LWC, covering a large $[\mathrm{NaOH}]$ span (in terms of its ratio to water) and at longer reaction time was, to our knowledge, still needed. Moreover, it remains uncertain whether the use of low (r) affects the type of NaCell possible to obtain. In the present study, we have attempted to fill these gaps. First, by exploring diffusion of $\mathrm{NaOH}$ from pre-mercerised cellulose into added unreacted cellulose pulp. Second, by mercerising cellulose pulp at two fixed low (r), with a broader variation of $[\mathrm{NaOH}]$. Third, by mercerising cellulose pulp at different low (r) with a fixed $[\mathrm{NaOH}]$. In mentioned studies, we have followed the DoA over time. Furthermore, we examine the type of Na-Cell formed at a sub-stoichiometric ratio with different $[\mathrm{NaOH}]$, as well as at different low (r) with a fixed $[\mathrm{NaOH}]$. We have measured the DoA quantitatively, using a partial least square (PLS) regression modelling on Raman spectroscopic data of produced samples. The type of Na-Cell formed at the studied conditions was qualitatively evaluated, using CP/MAS NMR measurements. The presented approach thus offers substantial information that can be helpful for the understanding of mercerisation at low (r) over time.

\section{Materials and methods}

\section{Materials}

The sample material was sheet sulphite dissolving cellulose pulp from a blend of spruce and pine, with $544 \mathrm{ml} \mathrm{g}^{-1}$ of viscosity (ISO 2470:1999), $95.3 \%$ of R 18 (ISO 699:1982) and 89.6\% of R 10 (ISO 699:1983) provided by Domsjö Fabriker $\mathrm{AB}$, Örnsköldsvik, Sweden. The moisture content (MC) of the pulp was $\leq 5 \%$, measured using a Mettler Toledo HG63 moisture analyser. For the preparation of alkaline aqueous solutions, $\mathrm{NaOH}$ from Sigma Aldrich (ACS reagent, $\geq 97.0 \%$ ) and degassed (by boiling) ultrapure Milli- $\mathrm{Q}_{2} \mathrm{O}$ was used. All the solutions were prepared in a temperature-controlled room at $25 \pm 0.1{ }^{\circ} \mathrm{C}$ and kept in vessels protected from atmospheric $\mathrm{CO}_{2}$. All alkaline solutions were used within $24 \mathrm{~h}$. Deionised $\mathrm{H}_{2} \mathrm{O}$ was used for washing the $\mathrm{NaOH}$ out of the mercerised samples.

\section{Grinding}

The sheet dissolving pulp was ground before performed experiments in a fine cutting mill (Netzsch, Germany) located in the pilot grinder at AkzoNobel, Örnsköldsvik Sweden. The obtained cellulose power had an average arithmetic length of $0.17 \mathrm{~mm}$.

Fibre length (size) measurement

The fibre length analysis was performed using PulpEye $^{\circledR}$ fibre module. The instrument uses highresolution optics to analyse fibre particles in a diluted suspension. The error of measurements is $\leq 1 \%$ on rayon fibres that are $2 \mathrm{~mm}$ long. The length limit for the analysed ground cellulose pulp was set to $0.01 \mathrm{~mm}$.

\section{Mercerisation at low $\mathrm{NaOH}$ stoichiometric excess}

For mercerisation, $5 \mathrm{~g}$ of dry dissolving ground cellulose pulp $\left(\mathrm{MC} \leq 5 \%\right.$ ), and $\mathrm{NaOH}_{\mathrm{aq}}$ were used. The $\mathrm{NaOH}_{\text {aq }}$ was sprayed using a modified airbrush 
(Biltema Sweden AB, item no. 17372), to ensure even distribution onto the cellulose pulp. The minimum amount of $\mathrm{NaOH}_{\mathrm{aq}}$ sprayed onto ground cellulose pulp in this study was $1.28 \mathrm{ml}$ of $50 \%[\mathrm{NaOH}]$ at $(\mathrm{r})=0.8$, while the maximum amount was $14.35 \mathrm{ml}$ of $10 \%$ $[\mathrm{NaOH}]$ at $(\mathrm{r})=1.3$. The mercerisation was carried out in a water jacketed z-mixer (kneader) at the viscose pilot plant at MoRe research in Örnsköldsvik, Sweden. The temperature during the mercerisation was $30^{\circ} \mathrm{C}$, and it was controlled by the $\mathrm{z}$-mixer, as well as an external water bath. The temperature uncertainty was estimated to $\pm 2{ }^{\circ} \mathrm{C}$. Photos of the mentioned setup are shown in the supplementary materials of one of our previous publications (Reyes et al. 2017). The samples were continuously mixed during the spraying of the $\mathrm{NaOH}_{\mathrm{aq}}$. Samples were collected at the set reaction times by stopping the mixing and removing samples. The mercerisation reaction was interrupted by washing the cellulose in excess of deionised $\mathrm{H}_{2} \mathrm{O}$, three to four times. The samples were then suspended in deionised $\mathrm{H}_{2} \mathrm{O}$, and the $\mathrm{pH}$ was checked for neutrality using indicator paper. Finally, the samples were dried at $40{ }^{\circ} \mathrm{C}$ in vacuum until constant weight.

\section{Set 1}

To analyse diffusion of $\mathrm{NaOHaq}$ from pre-mercerised ground dissolving cellulose pulp into added dry dissolving ground cellulose pulp (i.e. non-mercerised cellulose), two initial mercerisations were carried out, at $(r)=1.6$ and at $(r)=2.6$. In both mercerisations, $19.1 \mathrm{~N} \mathrm{NaOH}(50 \% \mathrm{w} / \mathrm{w})$ and 60 min reaction time was used. Thus, representing the pre-mercerised cellulose (Pre). The same amount of dry ground cellulose pulp was then added, and the diffusion of the $\mathrm{NaOH}$ from pre-mercerised cellulose into the added cellulose pulp was measured 5 (t5), 10 (t10) and 25 (t25) min after this addition. After the addition of cellulose, the average (r) values were 0.8 and 1.3 for the initial (r) values of 1.6 and 2.6, respectively.

\section{Set 2}

Dry dissolving cellulose pulp was mercerised at $(\mathrm{r})=0.8$ and at $(\mathrm{r})=1.3$. The $[\mathrm{NaOH}]$ used was $2.8 \mathrm{~N}(10 \% \mathrm{w} / \mathrm{w}), 6.1 \mathrm{~N}(20 \% \mathrm{w} / \mathrm{w}), 9.9 \mathrm{~N}(30 \%$ $\mathrm{w} / \mathrm{w}), 14.2 \mathrm{~N}(40 \% \mathrm{w} / \mathrm{w})$, and $19.1 \mathrm{~N}(50 \% \mathrm{w} / \mathrm{w})$. To clarify, (r) refers to the stoichiometric ratio between
$\mathrm{NaOH}$ and $\mathrm{AGU}$, while $[\mathrm{NaOH}]$ is defined as a variation that relates mainly to added water (i.e. the concentration of water) at the defined (r). Figure 1 illustrates the relation between water/AGU and (r) at different $[\mathrm{NaOH}]$. Samples were taken at 5, 25, 45, 90, and $1440 \mathrm{~min}$. However, the constant mixing was kept only for $90 \mathrm{~min}$. After that, the samples were kept at room temperature and rest until $1440 \mathrm{~min}$ were completed.

\section{Set 3}

Dry dissolving cellulose pulp was mercerised with $19.1 \mathrm{~N}(50 \% \mathrm{w} / \mathrm{w})$, and at $(\mathrm{r})=0.8,1.3,2.6$ (c.f. Fig. 1). The reaction time was 5, 25, 90, and $1440 \mathrm{~min}$. As was mentioned previously, after 90 min of mercerisation in the kneader, the samples were taken out and left at room temperature until 1440 min was reached.

\section{Calibration set samples}

We created a calibration set samples that represent different DoA levels in order to build a calibration model based on their average Raman spectra data evaluated by PLS. The obtained model was then used to predict the DoA of the mercerised samples at low (r). The method used to create the calibration set samples was previously reported by Albán Reyes et al. (2016). The calibration set consists of a mix of different weight proportions of dissolving cellulose pulp, depicted Cell I and fully mercerised material, depicted Cell II to represent different DoA levels

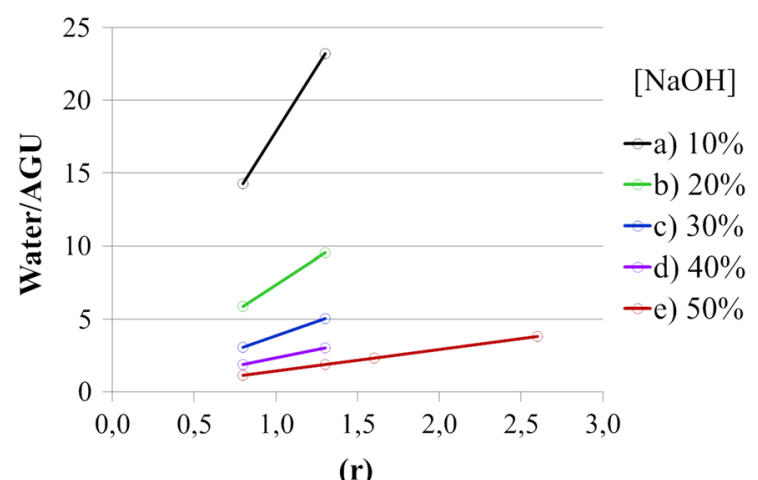

(r)

Fig. 1 Water/AGU ratio versus (r) at different $[\mathrm{NaOH}]$. a) $10 \%$, b) $20 \%$, c) $30 \%$, d) $40 \%$ and e) $50 \%$ [NaOH]. (r) $=\mathrm{NaOH} /$ AGU (anhydroglucose unit) stoichiometric ratio 
ranging from 0 (dissolving cellulose pulp) to 100 (fully mercerised material) in intervals of $10 \%(\mathrm{w} / \mathrm{w})$, as was described by Schenzel et al. (2009). The fully mercerised material was produced by mercerising dissolving cellulose pulp with an excess of $30 \%$ (w/w) $[\mathrm{NaOH}]$, at $3{ }^{\circ} \mathrm{C}$ for $1 \mathrm{~h}$. The sample was then left without stirring at room temperature for $24 \mathrm{~h}$, followed by washing until neutrality and drying. After mercerisation, the sample was considered to represent a fully mercerised material (Porro et al. 2007). After washing and drying it was considered to contain very low levels of Cell I, high levels of Cell II ( $\approx 95 \%$ ), as well as amorphous cellulose (Schenzel et al. 2009).

\section{Raman spectroscopy}

The Raman mapping data on a flat surface of the samples were acquired using a Renishaw InVia Raman spectrometer equipped with a CCD detector. The laser source was a $785 \mathrm{~nm}$ diode laser with maximum power of $300 \mathrm{~mW}$ and 1200 lines grating. The measurements were recorded in static mode, with a centre at $950 \mathrm{~cm}^{-1}$ (resulting in a spectral region of ca. $326-1494 \mathrm{~cm}^{-1}$ ), $1 \mathrm{~s}$ exposure time and $100 \%$ laser power. Raman shifts were calibrated using the built-in Si standard of the instrument. We used a $20 \times$ lens, and 10 microns step size for mapping. For every mapping 150-350 spectra were recorded. Cosmic ray effects were removed, and data noise-filtered using WiRE (version 3.0, Renishaw Plc, UK). The Raman spectra of Set 2 samples, at $(r)=1.3$, were recorded using a Bruker BRAVO portable instrument and OPUS version 7.8 (Bruker Optics GmbH, Ettlingen, Germany). In this case, the samples were placed in front of the laser beam exit manually, and spectra were recorded in the range of $326-1494 \mathrm{~cm}^{-1}$ at $4 \mathrm{~cm}^{-1}$ spectral resolution, using automatic integration times and 3 scans/sample. For all recorded Raman data, a baseline correction, Savitzky-Golay smoothing (Savitzky and Golay 1964), and a total area normalization was performed using a Matlab script provided by the Vibrational Spectroscopy Core Facility (http://www. kbc.umu.se/english/visp/download-visp/), the parameters used for baseline correction were $\lambda=1000$ and $p=0.001$, while for smoothing a polynomial order $=$ 1 and frame rate $=3$ was used. Finally, after preprocessing an average spectrum was calculated for each map and used for multivariate data analysis.
Partial least squares regression method

A PLS regression model (Eriksson et al. 2013; Geladi and Kowalski 1986) was used to correlate the averaged Raman spectra data of the calibration set samples to the known levels of dissolving cellulose pulp and fully mercerised material by using SIMCA (v.13.0.3.0, Umetrics AB, Umeå, Sweden). We used the Raman spectra data as X-data and the known levels of fully mercerised material as Y-data. The X-data were mean-centred, and the total number of components used in the model was two. The obtained PLS model was then used to predict the DoA of the mercerised samples at low (r) by using their average Raman spectra data as X-data and obtained their predict DoA value as a Y-data.

\section{Nuclear magnetic resonance spectroscopy} measurements

After $24 \mathrm{~h}$ of mercerisation, the appearance of the alkaline samples, Set 2 and Set 3 was still quite dry and heterogeneous. The produced alkaline samples were, in this semi-wet state, packed into a $4 \mathrm{~mm}$ zirconium oxide rotor for ${ }^{13} \mathrm{C} \mathrm{CP} / \mathrm{MAS}$ (cross-polarisation magic angle spinning) Nuclear Magnetic Resonance (NMR) measurements. The NMR spectra of the samples were recorded with a Bruker Avance III 500 spectrometer (Bruker Biospin GmbH, Reinstetten, Germany) at $298 \mathrm{~K}$ with a spin rate of $10,000 \mathrm{~Hz}$. Because of the high but differing alkalinity, the acquisition of NMR spectra varied for each sample within the given range, i.e. parentheses. A $3 \mu \mathrm{s}(3-6 \mu \mathrm{s}){ }^{1} \mathrm{H}$ excitation pulse was used followed by cross polarisation at $62.5 \mathrm{kHz}$ (31-62.5 kHz) with a 50-100\% ramped proton field up to $82 \mathrm{kHz}(37-82 \mathrm{kHz})$. The contact time for all samples were $1.5 \mathrm{~ms}$, and SPINAL-64 decoupling at $83 \mathrm{kHz}(37-83 \mathrm{kHz})$ was used. The recycle delay for all samples was $2.5 \mathrm{~s}$, giving an acquisition time of approximately $1.15 \mathrm{~h}$ per sample. The Adamantane $\mathrm{CH}_{2}$ peak was used as an external reference, set at 38.5 ppm (Morcombe and Zilm 2003). 


\section{Results and discussion}

Calibration samples and multivariate analysis of Raman spectroscopic data

To quantify the DoA of the mercerised samples at low (r), we built a calibration model using PLS regression of mean-centred Raman spectroscopic data of the calibration set samples (Eriksson et al. 2013). The Calibration samples consisted of a blend of dissolving cellulose pulp (Cell I, depicting DoA $=0 \%$ ) and fully mercerised material (Cell II, depicting DoA $=100 \%$ ) with their amounts known. The built calibration model could explain $\left(\mathrm{R}^{2}\right) 98 \%$ and predict $\left(\mathrm{Q}^{2}\right) 97 \%$ of the variation in the calibration set samples, the CVANOVA of the model results in a $p$ value $=1.98 * 10^{-05}<0.05$ (Fig. 2). The different conformations of the anhydroglucopyranose units in the chains of the crystalline structure of Cell I and Cell II allow a clear distinction between the vibration spectra of both crystalline forms. As a result, the main peaks in the loading line plot generated using the first component $\left(\mathrm{R}^{2}=98 \%\right)$ of the calibration model agree with the Raman bands for Cell I and Cell II described by Schenzel et al. (2009) and Atalla (1975) (Fig. S1, Supplementary material). The obtained model was then used to measure the DoA of the mercerised samples based on their Raman spectra.

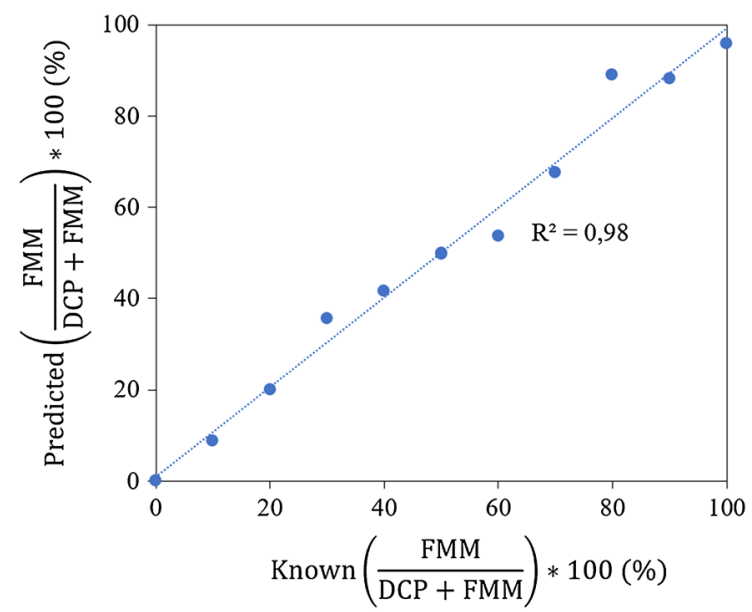

Fig. 2 Calibration model, using Raman spectra data of calibration set samples. Predicted DoA (\%) [here denoted as $\mathrm{FMM} /(\mathrm{DCP}+\mathrm{FMM})]$ versus the known DoA (\%) [FMM/ $(\mathrm{DCP}+\mathrm{FMM})]$ of calibration samples (black circles) and trend line. FMM refers to Fully Mercerised Material, while DCP to Dissolving Cellulose Pulp
We recorded Raman hyperspectral maps of both calibration samples and samples mercerised at low (r) to avoid local heterogeneities that could disturb single point measurements, and we averaged all spectra in each map. When recording the Raman hyperspectral maps of Set 1 , the number of maps per sample were increased to three, due to the large heterogeneity that those samples showed after cellulose addition (see replicates in Fig. S2 and Fig. S3, Supplementary material). The bars in Fig. 3 (Set 1) represent the average of the DoA of five different samples, scanned in three different places. Thus, the standard deviation refers to a total of 15 recorded maps.

Mercerisation at low $\mathrm{NaOH}$ stoichiometric excess

In the present study, the mercerisation at low (r) was performed using the same source of raw material, i.e. same batch, which consisted of softwood sulphite dissolving cellulose pulp from pine and spruce. Somewhat different results can be expected in DoA if other types of cellulose sources are used. We mercerised the dry dissolving cellulose pulp at $(\mathrm{r})=1.6$ and 2.6 with $50 \%[\mathrm{NaOH}]$ for $60 \mathrm{~min}$ (i.e. Pre-mercerised samples) and diluted the Pre-mercerised samples by adding dry dissolving cellulose pulp to an average value of $(r)=0.8$ and $(r)=1.3$. Thus, the diffusion of $\mathrm{NaOH}$ from the pre-mercerised cellulose (Pre) into added cellulose was analysed. DoA was re-measured for the total amount of cellulose

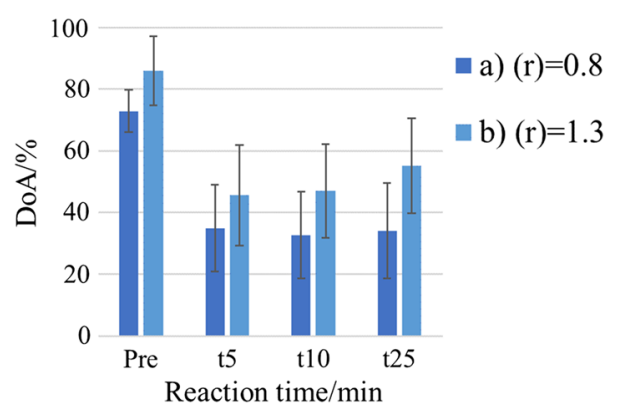

Fig. 3 DoA of mapping areas versus reaction time for samples where a) (r) = 0.8 and $b)(r)=1.3$ after subsequent addition of dry dissolving cellulose pulp, Set 1 . (r) $=\mathrm{NaOH} / \mathrm{AGU}$ (anhydroglucose unit) stoichiometric ratio, $[\mathrm{NaOH}]$ is $50 \% \mathrm{w} / \mathrm{w}$. "Pre" refers to the pre-mercerised cellulose, while t5 represents 5 min after addition of non-mercerised cellulose, i.e. the starting point for the diffusion study. $\mathrm{t} 10$ and $\mathrm{t} 25$ refers to $10 \mathrm{~min}$ and $25 \mathrm{~min}$ after addition of non-mercerised cellulose, respectively 
(Pre-mercerised plus added cellulose pulp) 5 min after the addition of unreacted dry dissolving cellulose pulp, denoted here as t5. As expected, the subsequent addition of unreacted dry cellulose pulp (Fig. 3) results in a decrease of the measured DoA, and it also increases the standard deviation. The first effect is ascribed to the unreacted cellulose (increasing the total cellulose by a factor of 2), while the second effect can be ascribed to the high heterogeneity in the samples after addition of unreacted cellulose pulp. No increase of DoA with time can be observed for samples at $(r)=0.8$. However, a slight increase of the measured DoA is observed after 10 min when activation was done at $(r)=1.3$, indicating a possible diffusion of the $\mathrm{NaOH}$. Although the sample at $(\mathrm{r})=0.8$ does not show any increase in DoA after the cellulose is added, diffusion cannot be dismissed. It is important to note that any difference in the results obtained in these samples are not statistically significant due to the large standard deviation of the measured DoA values in the samples after subsequent addition of cellulose, which suggests a high heterogeneity of the mixed sample, and thus any weak increase of the DoA would be invisible.

To address how the variation in water content (c.f. Fig. 1) influence the diffusion of $\mathrm{NaOH}$ and DoA at low (r), we have mercerised cellulose with $[\mathrm{NaOH}]$ between 10 and $50 \% \mathrm{w} / \mathrm{w}$ at $(\mathrm{r})=0.8$ and 1.3. The measured DoA for mercerised samples at $(r)=0.8$ from 5 to $90 \mathrm{~min}$ (Fig. 4), correspond to an average DoA of two replicate samples (Fig. S4 Supplementary material). We have previously reported that in our conditions, i.e. LWC mercerisation, the relative standard deviation for samples mercerised at $(\mathrm{r})=1.3$ and at $50 \%[\mathrm{NaOH}]$ is $17 \%$ at $5 \mathrm{~min}$ and $5 \%$ at $25 \mathrm{~min}$ (Reyes et al. 2017), thus indicating the reproducibility and deviation of the presented results. Note that the apparent maximum measured DoA values with respect to time, followed by an apparent decrease of it are due to the heterogeneity of the produced samples at this dry mercerisation condition, but not to a reconversion from the mercerised samples to Cell I. At our experimental conditions, the lowest DoA values is obtained at when $10 \%[\mathrm{NaOH}]$ is sprayed and no increase of DoA with time is observed for these samples. However, DoA at $(r)=1.3$ is almost twice as high, compared to at $(r)=0.8$. An explanation could be the adsorption of $\mathrm{NaOH}$ reported in the older literature (Coward and Spencer 1923; Richter and
Glidden 1940). In our case, adsorption of the $\mathrm{NaOH}$ by the cellulose fibre decreases the $\mathrm{NaOH}$ available in the free lye to a non-active concentration. It is known that at room temperature or higher, at least $10 \%[\mathrm{NaOH}]$ is needed for decent Na-Cell formation (Schenzel et al. 2009; Yokota et al. 1990). The phenomenon mentioned above is more pronounced at $(\mathrm{r})=0.8$. Moreover, when we increase the $[\mathrm{NaOH}]$ of the sprayed solution to $20 \%$, the measured DoA almost doubles for both (r) in all the studied reaction times (compare Fig. 4a to the Fig. 4b). The trend of these results were not totally unexpected, since increasing the $[\mathrm{NaOH}]$ leads to more effective collisions between the Na-ions and cellulose molecule, and smaller $\mathrm{NaOH}$-hydrates facilitates diffusion (Deshpande et al. 2008). Previous studies (Schenzel et al. 2009) have also reported an increase in Na-Cell formation (i.e. Cell II) when the $[\mathrm{NaOH}]$ is increased from 10 to $20 \%$, but at higher (r). The relative change is, however, stronger than reported for those conditions. Although our experimental conditions are quite dry, compared to mercerisation at higher ( $r$ ), a quick mercerisation can be observed with $10 \%$ and $20 \%$ of $[\mathrm{NaOH}]$ at both studied (r). This could be due to a fast diffusion of $\mathrm{NaOH}$, due to the relatively high amount of water at these concentrations. An example of this is shown in Fig. 4b: at $20 \%[\mathrm{NaOH}]$ the measured DoA does not clearly increase after $25 \mathrm{~min}$ for $(\mathrm{r})=0.8$ and not after $5 \mathrm{~min}$ for $(\mathrm{r})=1.3$. Previous studies have reported that the diffusion of $\mathrm{NaOH}$ decreased from $1.5^{\wedge} 10^{-9}$ to $1.1^{\wedge} 10^{-10} \mathrm{~m}^{2} / \mathrm{s}$ in pure $\mathrm{H}_{2} \mathrm{O}$ and in $7 \%$ cellulose solution respectively (Gavillon and Budtova 2007). Although the conditions in the mentioned study were different, it is thus highly probable that diffusion of $\mathrm{NaOH}$ is faster in aqueous solution than in cellulose particles. When we sprayed $30 \%$ and $40 \%$ of $[\mathrm{NaOH}]$, the highest DoA values for samples mercerised at $(\mathrm{r})=0.8$ appear. It seems like that at this substoichiometric ratio, the added amount of water when decreasing the $[\mathrm{NaOH}]$, i.e. $[\mathrm{NaOH}] \leq 20 \%$, limits the Na-Cell formation according to the equilibrium reaction as was suggested by us (Reyes et al. 2017). However, at this (r) the measured DoA increased over time, suggesting an apparent slow diffusion of $\mathrm{NaOH}$ at 30 and $40 \%[\mathrm{NaOH}]$, as can be seen in the Fig. $4 \mathrm{c}$, d. In contrast, the measured DoA at $(r)=1.3$ at the studied mentioned $\mathrm{NaOH}$ concentrations suggests that any diffusion is likely to be faster than $5 \mathrm{~min}$ (no observable increase of DoA after this time) and the 
Fig. 4 DoA versus reaction time for samples mercerised at $(\mathrm{r})=0.8$ (orange) and at $(\mathrm{r})=1.3$ (blue) and at different [NaOH], Set 2 . a $10 \%$, and b $20 \%$, c $30 \%$, d $40 \%$ and e $50 \%[\mathrm{NaOH}]$. (r) $=\mathrm{NaOH} / \mathrm{AGU}$ (anhydroglucose unit) stoichiometric ratio. (Color figure online) (a) $10 \%[\mathrm{NaOH}]$

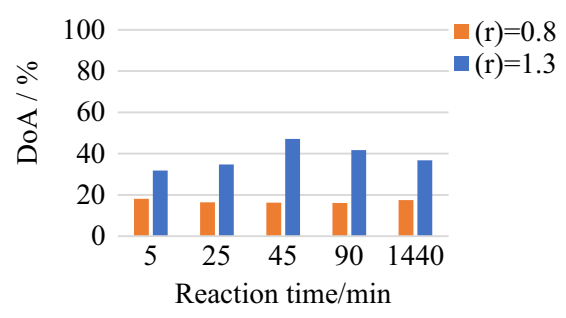

(c) $30 \%[\mathrm{NaOH}]$

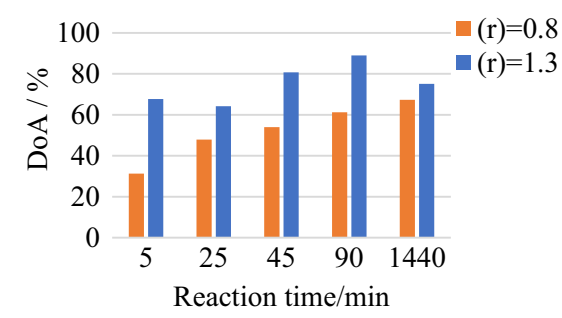

(e) $50 \%[\mathrm{NaOH}]$

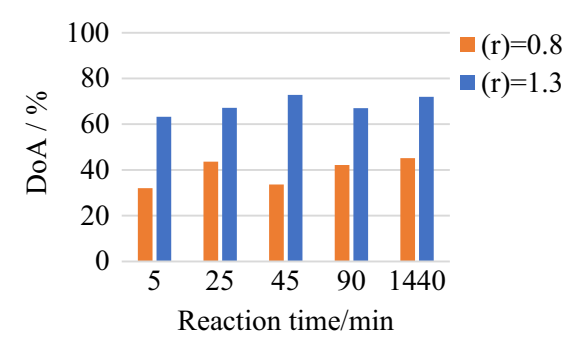

(b) $20 \%[\mathrm{NaOH}]$



(d) $40 \%[\mathrm{NaOH}]$

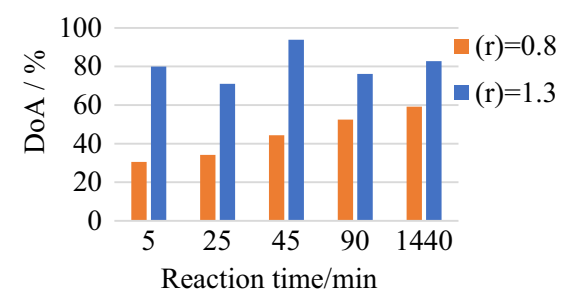

heterogeneity of the samples start to be more notable. At $50 \%[\mathrm{NaOH}]$ we reason that the water content is too low for significant diffusion to occur, and the data shows that these samples are more heterogeneous (Fig. 4e).

Our results confirm the importance of (r) on DoA earlier reported by us (Reyes et al. 2017), but further shows its complex dependence on the $[\mathrm{NaOH}]$ with a broader variation. An increase of the (r) from 0.8 to 1.3 increases the measured DoA in all studied $[\mathrm{NaOH}]$. Its importance is better illustrated in Fig. 5. Here it is shown that DoA increases when the (r) is increased at constant $[\mathrm{NaOH}](50 \% \mathrm{w} / \mathrm{w})$. The DoA doubles when (r) increases from 0.8 to 2.6 .

In addition, to unravel the equilibrium crystal structures of the Na-Cell complexes formed at $(r)=0.8$, we investigated samples mercerised for $24 \mathrm{~h}$ at room temperature by using CP/MAS NMR. As references, we used the NMR spectra of the dissolving cellulose pulp (depicting Cell I) and cellulose pulp

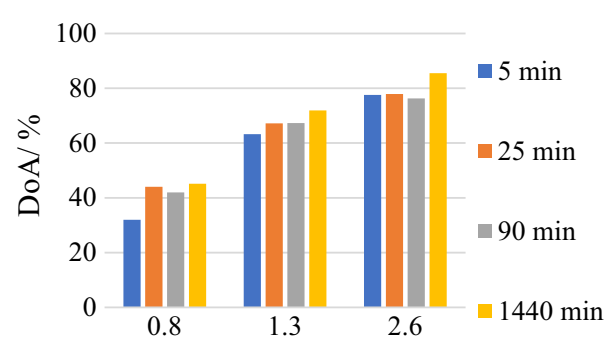

(r)

Fig. 5 DoA versus (r) for samples mercerised at $30{ }^{\circ} \mathrm{C}, 50 \%$ $[\mathrm{NaOH}] /(\mathrm{w} / \mathrm{w})$, and at different reaction times 5, 25, 90, and $1440 \mathrm{~min}$. Set 3. (r) $=\mathrm{NaOH} / \mathrm{AGU}$ (anhydroglucose unit) stoichiometric ratio

alkalised with $18 \%[\mathrm{NaOH}]$ (depicting $\mathrm{Na}-\mathrm{Cell} \mathrm{I}$ ) and $40 \%[\mathrm{NaOH}]$ (depicting Na-Cell II) at (r) $\geq 20$, at room temperature and for $24 \mathrm{~h}$. Previous work has shown complete transformation to the Na-Cell at the used conditions, respectively, thereby giving reference spectra of both Na-Cell allomorphs (Porro et al. 2007). The CP/MAS ${ }^{13} \mathrm{C}$ NMR spectra of the references 
samples and mercerised samples at low (r) are shown in Figs. 6 and 7, in these figures the signals in the spectra regions of 109-102, 91-82, 80-70, and 66-60 ppm belong to the signal patterns of $\mathrm{C} 1, \mathrm{C} 4$, C2-C3-C5, and C6 carbons, respectively (Halonen et al. 2013; Isogai et al. 1989; Yokota et al. 1990).

The NMR spectra of semi-wet mercerised samples at $(r)=0.8$ shows that pure Na-Cell is not formed (Fig. 6). This agrees with the measured DoA from the PLS model of the Raman data (Fig. 4). All the NMR spectra of samples mercerised at this (r), thus, shows that the samples still contain unreacted material. Keeping in mind that it is likely that the (r) must be $\geq 1$ in order to have a stoichiometric amount of $\mathrm{NaOH}$ per AGU (Albán Reyes et al. 2017; Nishimura et al. 1991), it is interesting to observe that at this substoichiometric ratio combined with such a low $[\mathrm{NaOH}]$ as $10 \%$ we can start to observe changes in $\mathrm{C} 1, \mathrm{C} 4$ and $\mathrm{C} 6$ of the NMR spectra of the cellulose
(Fig. 6d). When the $[\mathrm{NaOH}]$ is increased to 20 , and $30 \%$ (Fig. 6e, f), fewer features of the dissolving cellulose pulp are observed and there are more similarities with Na-Cell I, most noticeably for cellulose mercerised with $30 \%[\mathrm{NaOH}]$. When the $[\mathrm{NaOH}]$ increases to $40 \%$ and $50 \%$ (Fig. $6 \mathrm{~g}, \mathrm{~h}$ ), the NMR spectra of the samples have similarities to the cellulose pulp and Na-Cell II. The type of Na-Cell formed at $20 \%, 40 \%$ and $50 \%[\mathrm{NaOH}]$ agree with those already published when ( $\mathrm{r}$ ) $>40$ is used (Porro et al. 2007). However, the initial change observed in the starting material at $10 \%[\mathrm{NaOH}]$ differs from the observation given in the mentioned study, where the NMR spectra of the cellulose remain intact at $[\mathrm{NaOH}]$ below 13\%. In agreement with our observations, milled cotton linter treated with $10 \%[\mathrm{NaOH}]$ at $(\mathrm{r}) \approx 44$ resulted in a transition from Cell I to Na-Cell I (Yokota et al. 1990). Furthermore, Schenzel et al. (2009) observed a decrease in Cell I content when



Fig. $6{ }^{13} \mathrm{C} \mathrm{CP/MAS} \mathrm{NMR} \mathrm{spectra} \mathrm{of} \mathrm{dissolving} \mathrm{cellulose} \mathrm{pulp}$ after $24 \mathrm{~h}$ of mercerisation at different $[\mathrm{NaOH}]$, room temperature and at $(r)=0.8$, Set 2: (a) dissolving cellulose pulp, representing Cell I, (b) reference sample, representing Na-Cell I, and (c) reference sample, representing Na-Cell II. The $[\mathrm{NaOH}]$ used were (d) $10 \%$, (e) $20 \%$, (f) $30 \%$, (g) $40 \%$, and (h) $50 \% \mathrm{w} / \mathrm{w}$ 


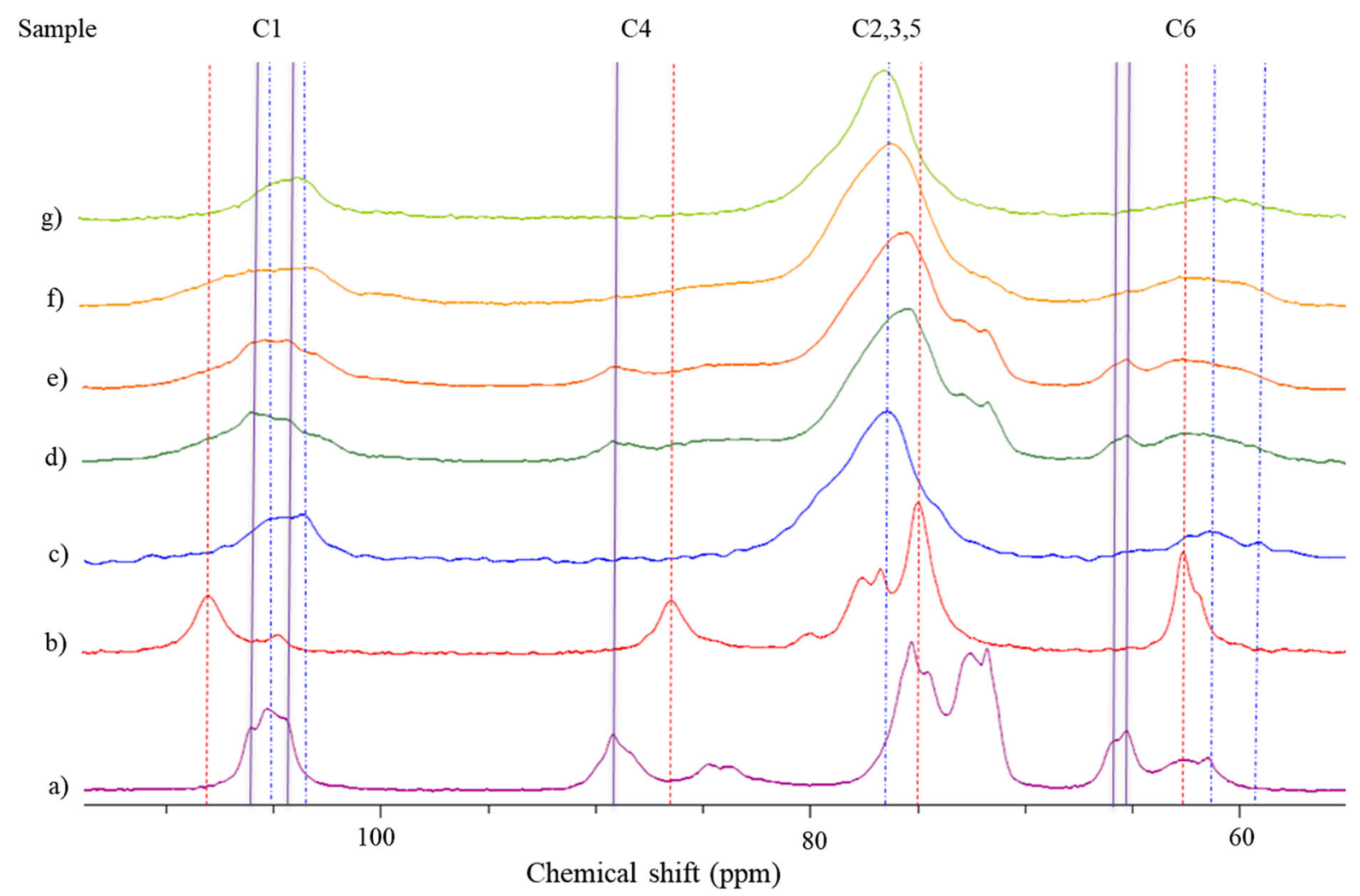

Fig. $7{ }^{13} \mathrm{C} \mathrm{CP/MAS} \mathrm{NMR} \mathrm{spectra} \mathrm{of} \mathrm{dissolving} \mathrm{cellulose} \mathrm{pulp}$ after $24 \mathrm{~h}$ of mercerisation at different (r), $50 \%$ [NaOH], and at room temperature, Set 3: (a) dissolving cellulose pulp,

sulphite pulp was mercerised using $[\mathrm{NaOH}]$ between 6 and $12 \%$ at $(r) \approx 15$. The observed discrepancy thus seems to be due to, e.g. raw material and pre-treatment of the cellulose. A more interesting difference is seen when the cellulose is alkalised with $30 \%[\mathrm{NaOH}]$ at (r) $=0.8$ (Fig. 6f). Already in 1939, Sobue et al. found that Na-Cell II is formed when the $[\mathrm{NaOH}]$ was $30 \%$. This was later confirmed by Porro et al. (2007). At our experimental conditions, however, only the signals assigned to Na-Cell I [e.g. $108.1 \mathrm{ppm}$ (C1), $86.6 \mathrm{ppm}$ (C4), and $62.7 \mathrm{ppm}$ (C6)] are observed. This indication of $\mathrm{Na}-\mathrm{Cell} \mathrm{I}$, which was unexpected from literature, is probably due to a change in the AGU/ $\mathrm{NaOH} / \mathrm{H}_{2} \mathrm{O}$ equilibrium due to the much lower ( $\mathrm{r}$ ) than what is reported previously. As noted by Porro et al. (2007) applied constraints conditions (e.g. here low (r) at $30 \%[\mathrm{NaOH}])$ can probably lead to different cellulose allomorphs. In contrast, Fig. 7 shows that the Na-Cell allomorph formed at higher $[\mathrm{NaOH}](50 \%$ $\mathrm{w} / \mathrm{w})$ and at $0.8<(\mathrm{r})<2.6$ seems not to be influenced by the (r). In this figure, all the spectra show representing Cell I, (b) reference sample, representing Na-Cell I, and (c) reference sample, representing Na-Cell II. The (r) used were (d) 0.8 , (e) 1.0 , (f) 1.3, (g) 2.6

similarities to Na-Cell II, where the feature of this type of Na-Cell become more pronounced with increased (r). In summary, NMR measurements suggest that at the studied temperature, the concentration of $\mathrm{NaOH}$ mainly determines the Na-Cell allomorph. However, close to the transition area (c.f. Porro et al. 2007), (r) also seems to be of importance.

\section{Diffusion of $\mathrm{NaOH}$ at low $\mathrm{NaOH}$ stoichiometric excess}

In our view, mercerisation at low (r) could, in part, proceed through diffusion of $\mathrm{NaOH}$ in already swollen ground cellulose pulp; this phenomenon being more pronounced at sub-stoichiometric (r), Set 2. According to literature, swelling of cellulose at mercerisation conditions i.e. $[\mathrm{NaOH}] \geq 10 \%$, causes a change in the morphology of the cellulose, transforming it into a highly swollen material (Na-cell) (Budtova and Navard 2016). Because of the morphology change, we reason that swelling facilitates a further diffusion 
of $\mathrm{NaOH}$ into more cellulose fibres, leading to a continued and controlled Na-Cell formation over time. As noted by us in a previous study, this controlled feedback of swelling $\rightarrow$ diffusion of $\mathrm{NaOH} \rightarrow \mathrm{Na}-$ Cell formation $\rightarrow$ swelling seems to be important for the DoA at low (r) (Reyes et al. 2017). It is known that, at mercerisation conditions, the cellulose swells better at low $[\mathrm{NaOH}]$ (Richter and Glidden 1940), and the diffusion of $\mathrm{NaOH}$ in aqueous media is fast (Gavillon and Budtova 2007). Therefore, the diffusion of $\mathrm{NaOH}$ into well-swollen cellulose at low (r) should benefit from low $[\mathrm{NaOH}]$ (Illustration $\mathrm{S} 1$, supplementary material). The data suggests that this diffusion is fast at $[\mathrm{NaOH}] \leq 20 \%$, when mercerisation is performed at $(\mathrm{r})=0.8$ and at $(\mathrm{r})=1.3$ (Fig. 4). Thus, it is possible that the $\mathrm{NaOH}$ diffuse through the well-swollen cellulose, which makes the diffusion too fast to notice on our timescale. At $30 \%$ and $40 \%[\mathrm{NaOH}]$, however, the $\mathrm{H}_{2} \mathrm{O}$ content at $(\mathrm{r})=0.8$ is not high enough to allow good swelling. Thus, a quick diffusion of $\mathrm{NaOH}$ through the system cannot occur, and the data shows that the measured DoA slowly increases with time. At (r) $=1.3$ more $\mathrm{H}_{2} \mathrm{O}$ is present, and the diffusion through swollen cellulose is faster (c.f. Fig. 1). Hence no increase of DoA can be observed with time. This explains why the amount of water in the system, given by the combination of both (r) and $[\mathrm{NaOH}]$, has an influence on the apparent diffusion rate of $\mathrm{NaOH}$, affecting the time it takes for the system to reach a steady-state. As was discussed above, the alkali adsorption onto cellulose surfaces could also affect the diffusion of the $\mathrm{NaOH}$ when $(\mathrm{r})<1$.

\section{Conclusions}

In this study, the gradual increase of the DoA observed at some conditions, indicates a continuous $\mathrm{Na}-\mathrm{Cell}$ formation. A plausible explanation is the diffusion of $\mathrm{NaOH}$ through poorly swollen cellulose fibres. This diffusion would be affected by the amount of water present in the system given by $[\mathrm{NaOH}]$ and/or (r). The amount of time required for the system to reach its equilibrium is thus influenced. At sub-stoichiometric conditions, such diffusion was clearly observed at $30 \%$ and $40 \%[\mathrm{NaOH}]$. Our data show a remarkable influence of (r) on DoA and its complex dependence on the $[\mathrm{NaOH}]$. At $(\mathrm{r}) \leq 1.3$, the lowest DoA was found at $(\mathrm{r})=0.8$ and $10 \%[\mathrm{NaOH}]$, while the highest value was observed at $(\mathrm{r})=1.3$ and $20 \%[\mathrm{NaOH}]$. Lastly, ${ }^{13} \mathrm{C}$ CP/MAS NMR measurements allow us to identify the Na-Cell type formed at low (r). Our data shows that, at a fixed temperature, the $[\mathrm{NaOH}]$ plays an important role in determining the form of $\mathrm{Na}$-cell, as it does when mercerisation is done at high (r). However, close to the transition area between Na-Cell I and Na-Cell II, (r) also seems to be of importance.

Acknowledgments This research was supported by the Industrial Doctoral School (IDS) at Umeå University (UmU), AkzoNobel Functional Chemicals, Domsjö Fabriker AB, Bio4Energy, and SP Processum. We thank the Vibrational Spectroscopy and NMR platform at KBC (UmU) for experimental guidance and assistance.

Open Access This article is distributed under the terms of the Creative Commons Attribution 4.0 International License (http:// creativecommons.org/licenses/by/4.0/), which permits unrestricted use, distribution, and reproduction in any medium, provided you give appropriate credit to the original author(s) and the source, provide a link to the Creative Commons license, and indicate if changes were made.

\section{References}

Albán Reyes DC, Skoglund N, Svedberg A, Eliasson B, Sundman O (2016) The influence of different parameters on the mercerisation of cellulose for viscose production. Cellulose 23:1061-1072. https://doi.org/10.1007/s10570-0160879-0

Albán Reyes DC, Gorzsas A, Stridh K, de Wit P, Sundman O (2017) Alkalization of dissolving cellulose pulp with highly concentrated caustic at low $\mathrm{NaOH}$ stoichiometric excess. Carbohydr Polym 165:213-220. https://doi.org/10. 1016/j.carbpol.2017.02.045

Atalla RH (1975) Raman spectral studies of polymorphy in cellulose. Part 1, Celluloses I and II. IPC Technical paper series no. 19

Berglund L, Johansson KA, Sundberg K (2009) Process for the manufacture of methyl cellulose ether. US Patents 7,504,498 B2

Borysiak S, Garbarczyk J (2003) Applying the WAXS method to estimate the supermolecular structure of cellulose fibers after mercerization. Fibers Text East Eur 11:44

Boström P, Karlson L (2013) Associative water-soluble cellulose ethers. US Patents 8,487,089 B2

Budtova T, Navard P (2016) Cellulose in $\mathrm{NaOH}$-water based solvents: a review. Cellulose 23:5-55. https://doi.org/10. 1007/s10570-015-0779-8

Coward HF, Spencer L (1923) The absorption of caustic soda solutions by cotton. J Text Inst Trans 14:T32-T45. https:// doi.org/10.1080/19447022308661230

Deshpande MD, Scheicher RH, Ahuja R, Pandey R (2008) Binding strength of sodium ions in cellulose for different 
water contents. J Phys Chem B 112:8985-8989. https://doi. org/10.1021/jp8020547

Eriksson L, Byrne T, Johansson E, Trygg J, Vikström C (2013) Multi-and megavariate data analysis basic principles and applications, 3rd edn. Umetrics Academy, Malmö

Gavillon R, Budtova T (2007) Kinetics of cellulose regeneration from cellulose- $\mathrm{NaOH}$-water gels and comparison with cellulose-N-methylmorpholine-N-oxide-water solutions. Biomacromolecules 8:424-432. https://doi.org/10.1021/ bm060376q

Geladi P, Kowalski BR (1986) Partial least-squares regression: a tutorial. Anal Chim Acta 185:1-17. https://doi.org/10. 1016/0003-2670(86)80028-9

Gupta PK, Uniyal V, Naithani S (2013) Polymorphic transformation of cellulose I to cellulose II by alkali pretreatment and urea as an additive. Carbohydr Polym 94:843-849. https://doi.org/10.1016/j.carbpol.2013.02.012

Halonen H, Larsson PT, Iversen T (2013) Mercerized cellulose biocomposites: a study of influence of mercerization on cellulose supramolecular structure, water retention value and tensile properties. Cellulose 20:57-65. https://doi.org/ 10.1007/s10570-012-9801-6

Isogai A, Usuda M, Kato T, Uryu T, Atalla RH (1989) Solidstate CP/MAS carbon-13 NMR study of cellulose polymorphs. Macromolecules 22:3168-3172. https://doi.org/ 10.1021/ma00197a045

Jin E, Guo J, Yang F, Zhu Y, Song J, Jin Y, Rojas OJ (2016) On the polymorphic and morphological changes of cellulose nanocrystals (CNC-I) upon mercerization and conversion to CNC-II. Carbohydr Polym 143:327-335. https://doi.org/ 10.1016/j.carbpol.2016.01.048

Langan P, Nishiyama Y, Chanzy H (2001) X-ray structure of mercerized cellulose II at $1 \AA$ resolution. Biomacromolecules 2:410-416. https://doi.org/10.1021/bm005612q

Morcombe CR, Zilm KW (2003) Chemical shift referencing in MAS solid state NMR. J Magn Reson 162:479-486. https://doi.org/10.1016/S1090-7807(03)00082-X

Mozdyniewicz DJ, Sixta H (2012) Carbohydrate degradation reactions during alkaline steeping of dissolving pulp-influence of air exclusion. Lenz Berich 90:103-107

Nishimura H, Okano T, Sarko A (1991) Mercerization of cellulose. 5. Crystal and molecular-structure of NA-cellulose I. Macromolecules 24:759-770. https://doi.org/10.1021/ ma00003a020

Okano T, Sarko A (1985) Mercerization of cellulose. 2. Alkali cellulose intermediates and a possible mercerization mechanism. J Appl Polym Sci 30:325-332. https://doi.org/ 10.1002/app.1985.070300128
Philipp B, Fink H, Kunze J, Purz H (1983) Recent results on formation and structure of alkali cellulose [Cotton linters]. In: Proceed technical assoc of the pulp and paper industry (USA)

Porro F, Bedue O, Chanzy H, Heux L (2007) Solid-state 13C NMR study of Na-cellulose complexes. Biomacromolecules 8:2586-2593

Ranby BG (1952) The mercerisation of cellulose. 1. A thermodynamic discussion. Acta Chem Scand 6:101-115

Reyes DCA, Gorzsas A, Stridh K, de Wit P, Sundman O (2017) Alkalization of dissolving cellulose pulp with highly concentrated caustic at low $\mathrm{NaOH}$ stoichiometric excess. Carbohydr Polym 165:213-220. https://doi.org/10.1016/j. carbpol.2017.02.045

Richter GA, Glidden KE (1940) Cellulose sheet swelling effect of temperature and concentration of sodium hydroxide solutions. Ind Eng Chem 32:480-486. https://doi.org/10. 1021/ie50364a008

Savitzky A, Golay MJE (1964) Smoothing and differentiation of data by simplified least squares procedures. Anal Chem 36:1627-1639. https://doi.org/10.1021/ac60214a047

Saxell H, Heiskanen I, Axrup L, Hensdal CL, Jokela V (2015) Method for the preparation of cellulose ethers with a high solids process, product obtained and uses of the product. US Patents 2015/0094464 A1

Schenzel K, Almlöf H, Germård U (2009) Quantitative analysis of the transformation process of cellulose I to cellulose II using NIR FT Raman spectroscopy and chemometric methods. Cellulose 16:407-415

Sisson WA, Saner WR (1941) The effect of the temperature and the concentration of sodium hydroxide on the $\mathrm{x}$-ray diffraction behavior of raw and of degraded cotton. J Phys Chem 45:717-730. https://doi.org/10.1021/j150410a001

Sobue H, Kiessig H (1939) The cellulose-sodium hydroxidewater system as a function of the temperature. $\mathrm{Z}$ Phys Chem B 43:309-328

Wilkes AG (2001) 3-the viscose process A2-Woodings, Calvin. In: Regenerated cellulose fibres. Woodhead Publishing, pp 37-61. http://dx.doi.org/10.1533/978185573 7587.37

Yokota H, Sei T, Horii F, Kitamaru R (1990) 13C CP/MAS NMR study on alkali cellulose. J Appl Polym Sci 41:783-791. https://doi.org/10.1002/app.1990.070410325

Yue Y, Han G, Wu Q (2013) Transitional properties of cotton fibers from cellulose I to cellulose II structure. BioResources 8:6460-6471 